\title{
Rectal diclofenac for prevention of post-endoscopic retrograde cholangiography pancreatitis
}

\author{
Héctor F. Losada ${ }^{1,2,3}$, Pablo I. San Martin ${ }^{1}$, Andrés I. Troncoso ${ }^{1,2}$, Jorge A. Silva ${ }^{1,2,3}$ \\ ${ }^{1}$ Hepato-Bilio-Pancreatic Surgery Team, Department of Surgery, Traumatology and Anesthesiology, Universidad de la Frontera, Temuco, Chile; \\ ${ }^{2}$ Hepato-Bilio-Pancreatic Surgery Team, Hernán Henríquez Aravena Hospital, Temuco, Chile; ${ }^{3}$ Hepato-Bilio-Pancreatic Surgery Team, Clínica \\ Alemana Temuco, Temuco, Chile \\ Contributions: (I) Conception and design: HF Losada, PI San Martin, AI Troncoso; (II) Administrative support: All authors; (III) Provision of \\ study material: HF Losada, PI San Martin; (IV) Collection and assembly of data: HF Losada, PI San Martin, AI Troncoso; (V) Data analysis and \\ interpretation: All authors; (VI) Manuscript writing: All authors; (VII) Final approval of manuscript: All authors. \\ Correspondence to: Héctor F. Losada. Hepato-Bilio-Pancreatic Surgery Team, Department of Surgery, Traumatology and Anesthesiology, Universidad \\ de la Frontera, Temuco, Chile. Email: hector.losada@ufrontera.cl.
}

Background Acute pancreatitis is an important complication of endoscopic retrograde cholangiography (ERC), occurring between $1-10 \%$ of patients. Several randomized controlled trials and meta-analyses have demonstrated the effectiveness of nonsteroidal anti-inflammatories (NSAIDs) such as diclofenac and indomethacin as a post-ERC pancreatitis (PEP) prophylaxis. The aim is to determine if the rectal diclofenac use reduces the PEP rate.

Methods: Retrospective cohort study. Subjects were included who underwent ERC for different indications in a tertiary center between January 2015 and June 2016. Two groups were analyzed: group A (without diclofenac use) and group B (with use of diclofenac as PEP prophylaxis). Biodemographic, technical and mortality variables were measured.

Results: The total cohort was 116 patients, 67 in group A and 49 in group B. The average age was $61.9 \pm 17.8$ and $58.3 \pm 15.8$ years, respectively $(\mathrm{P}=0.2606)$. Gender distribution showed a women predominance in both groups $(\mathrm{P}=0.933)$. Of the technical variables measured, the precut showed a statistically significant relationship to PEP $(\mathrm{P}=0.013)$. Of the total cohort, 8.6\% developed acute pancreatitis after an ERC: four in group $A$ and six in group $B(P=0.196)$. In those who developed PEP $(n=10)$, six patients developed severe acute pancreatitis (SAP). The average hospitalization for PEP was $32.2 \pm 34$ days $(\mathrm{P}=0.881)$. No patients died, not were there any adverse reactions to the drug.

Conclusions: Rectal diclofenac administered at the beginning of the ERC did not reduce the PEP rate in this patients cohort.

Keywords: Endoscopic retrograde cholangiography (ERC); pancreatitis; prophylaxis; diclofenac; post-endoscopic retrograde cholangiography pancreatitis $(\mathrm{PEP})$

Submitted Oct 19, 2019. Accepted for publication Aug 04, 2020.

doi: 10.21037/apm-19-395

View this article at: http://dx.doi.org/10.21037/apm-19-395

\section{Introduction}

Acute pancreatitis is an important complication of endoscopic retrograde cholangiography (ERC), occurring in $1-10 \%$ of patients.

Most patients develop mild to moderate pancreatitis, and only between $0.3-0.6 \%$ require some type of surgery $(1,2)$.
Several theories exist regarding the post-ERC pancreatitis (PEP) pathogenesis, but the most accepted is the occurrence of a mechanical trauma on papilla or the pancreatic sphincter, temporarily obstructing the pancreatic juice release. Another theory suggests that the increase in hydrostatic pressure in the pancreatic duct due to the 
injection of contrast or saline solution damages parenchyma $(3,4)$. Regardless of the mechanism, an events cascade begins which results in the proteolytic enzymes activation, causing pancreas autodigestion and acinar secretion (5) alteration. This inflammatory cascade activation is the cause of local and systemic effects. The proposed surgeries to prevent PEP seek to break this inflammatory cascade $(3,6,7)$.

Several alternatives, both mechanical and pharmacological, have been assessed as a PEP prevention, but without success. Nonsteroidal anti-inflammatories (NSAIDs) are powerful inhibitors of phospholipase A2, which is fundamental for the inflammatory cascade activation (8).

Several randomized controlled trials and meta-analyses have demonstrated the effectiveness of NSAIDs such as diclofenac and indomethacin as PEP prophylaxis.

Our aim is to evaluate whether the administration of rectal diclofenac before the ERC reduces PEP rate.

\section{Methods}

\section{Design}

Retrospective cohort study.

\section{Population}

This study was conducted at a tertiary center in Temuco, Chile, between January 2015 and June 2016 (18 months). Two groups were analyzed $(n=116)$ that underwent an ERC for different indications. All the patients who had an ERC were included; there were no exclusion criteria. Group A contained patients who underwent an ERC without diclofenac, and in group B diclofenac was used as PEP prophylaxis.

From August 2015, rectal diclofenac (Laboratorio Chile) was administered to all patients undergoing an ERC as PEP prophylaxis at the beginning of the procedure. Prior to this period, no prophylaxis was used.

\section{Management}

Two members of the hepatobiliopancreatic surgery team (JSA and HLM) perform ERC 2-3 times per week in the hospital. On most occasions they are the members of the team during the procedures, and decisions are made jointly.

About the bile duct cannulation techniques, the team uses papillotomy or a biliary cannula with a hydrophilic guide. The precut is used when three unsuccessful bile duct cannulation attempts have been made or cannulation or repeated contrast injections have been used in the Wirsung duct.

After the procedure the patient remains with nothing by mouth for approximately 12 hours. A clinical assessment occurs and if the patient is asymptomatic, refeeding is started (9).

The use of pancreatic prostheses to prevent PEP was not used routinely and according to the surgeon's preference.

Other measures such as adrenalin instillation on the mucosa or lidocaine were not routine.

The team does not do rescue ERC in a case where patients have PEP in the early post-ERC period.

In our center, we do not perform routine post-ERC amylase or lipase control, only according to the patient's clinical picture.

PEP refers to patients with suggestive abdominal pain and serum amylase and/or lipase levels three times higher than normal laboratory values.

\section{Study variables}

Biodemographic variables and technical variables of ERC and mortality were described.

(I) Biodemographic variables: age, gender.

(II) Technical variables: difficult cannulation, thin bile duct, cannulation/Wirsung contrast, biopsy, sphincterotomy, prosthesis, PEP, indications for ERC in both groups.

\section{Sample size}

The study by Khoshbaten (10) was used to calculate the sample size, which showed a $4.4 \%$ pancreatitis rate in the diclofenac group and $26 \%$ in the placebo group. With a statistical significance of $95 \%$ and a power of $80 \%$, a sample of 42 patients per group was obtained, with a total of 84 patients.

\section{Statistical tools}

Descriptive statistics were used with central tendency and dispersion measure, and analytical statistics with a $t$-test for continuous variables and $\mathrm{chi}^{2}$ or Fisher's exact test for dichotomous variables. The database was done in Excel $^{\circledR}$ and the analysis was performed in Stata ${ }^{\circledR} 10.0$, (StataCorp. 2007. Stata Statistical Software: Release 10. College Station, TX: StataCorp LP). EPIINFO was used to calculate the 
Table 1 Indications of ERC in both groups

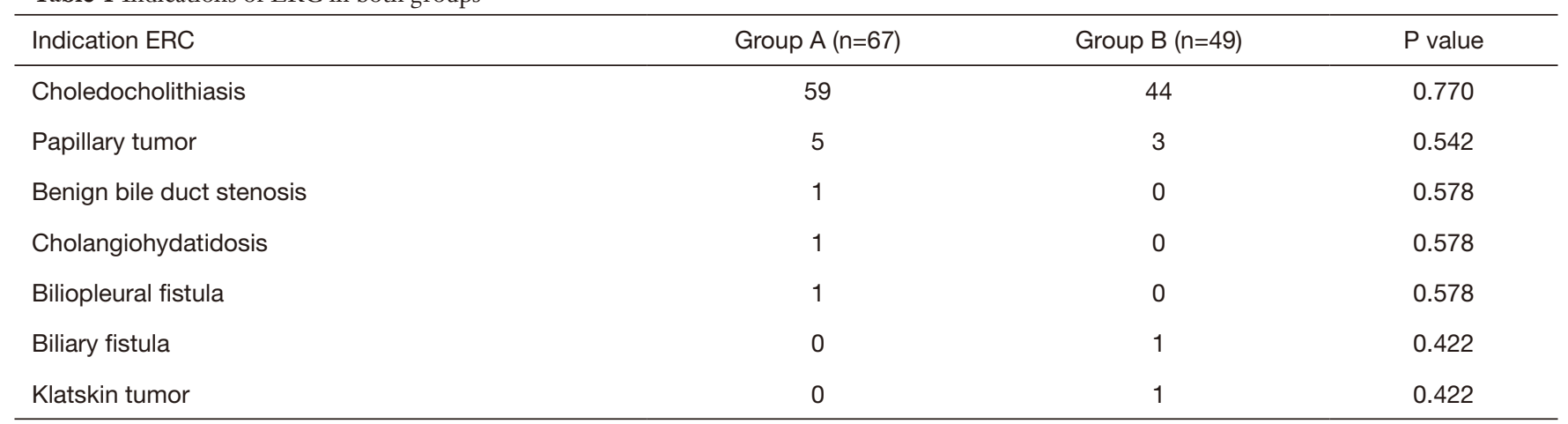

ERC, endoscopic retrograde cholangiography.

Table 2 Technical characteristics of ERC

\begin{tabular}{|c|c|c|c|}
\hline Technical characteristics ERC & Group A & Group B & $P$ value \\
\hline Precut $(n=15)$ & 13 & 2 & 0.013 \\
\hline Sphincterotomy $(n=10)$ & 3 & 7 & 0.064 \\
\hline Difficult cannulation $(n=19)$ & 13 & 6 & 0.303 \\
\hline Cannulation Wirsung $(n=5)$ & 4 & 1 & 0.294 \\
\hline Wirsung contrast ( $n=12)$ & 7 & 5 & 0.609 \\
\hline Installation of prosthesis $(n=29)$ & 16 & 13 & 0.745 \\
\hline Biopsy sampling ( $n=8)$ & 6 & 2 & 0.262 \\
\hline
\end{tabular}

ERC, endoscopic retrograde cholangiography.

sample size.

\section{Ethical aspects}

The study protocol was approved by the scientific ethics committee of the Araucanía South Health Service (Chile) and by the research group of the Department of Surgery Traumatology and Anesthesiology at the Universidad de la Frontera. All persons gave their informed consent prior to their inclusion in the study (ID: 004). The study was conducted in accordance with the Declaration of Helsinki (as revised in 2013).

\section{Results}

The total cohort was 116 patients. Group A (without diclofenac) contains 67 patients and group B (with diclofenac) contains 49 patients.

The indications of ERC for the cohort in both groups were similar, with choledocholithiasis being the main indication, followed by papillary tumors (Table 1).

Within measured biodemographic variables, the gender distribution showed a women predominance in both groups, with no significant differences between the two groups (68\% vs. 69\%) $(\mathrm{P}=0.933)$. The average age was similar in groups $\mathrm{A}$ and $\mathrm{B}, 61.9 \pm 17.8$ and $58.3 \pm 15.8$ years, respectively $(\mathrm{P}=0.2606)$.

Of all patients, $8.6 \%$ developed post-ERC acute pancreatitis: four patients in group $\mathrm{A}$ and six patients in group $\mathrm{B}(\mathrm{P}=0.196)$.

Table 2 illustrates the relationship between ERC technical variables and PEP outcome. Only the precut demonstrated 
Table 3 Characteristics and indicators in the PEP group

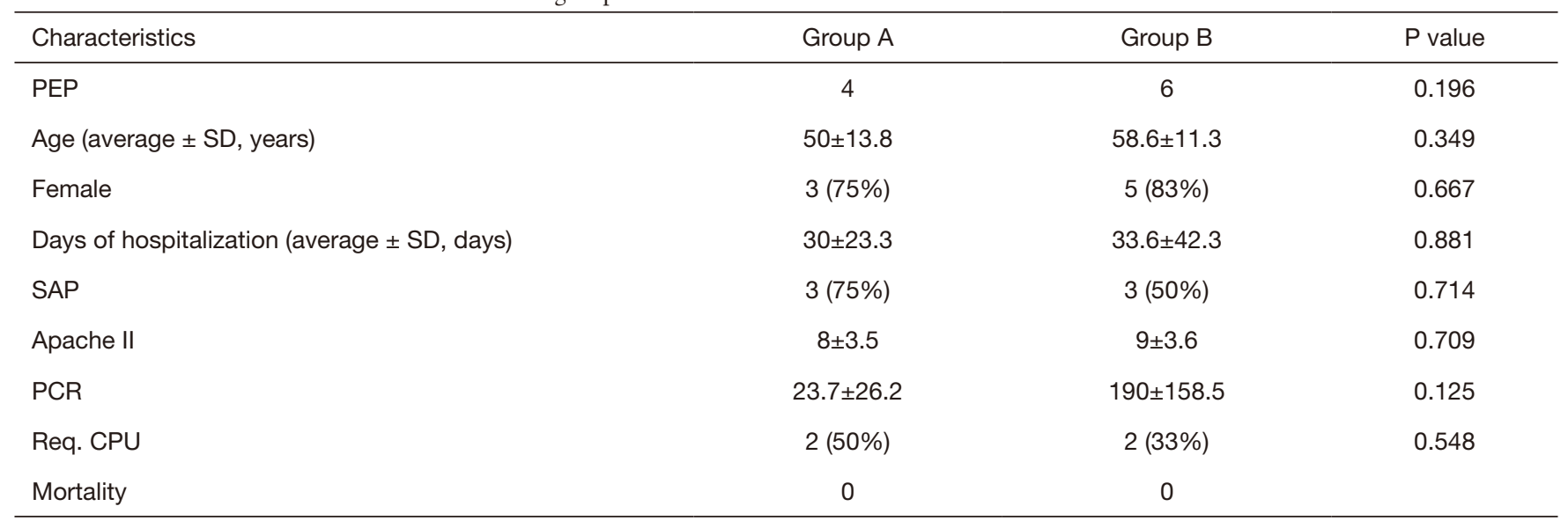

PEP, post-endoscopic retrograde cholangiography pancreatitis; PCR, C-reactive protein; CPU, critical patient unit; SAP, severe acute pancreatitis.

a statistically significant relation $(\mathrm{P}=0.013)$.

The patients who developed PEP $(\mathrm{n}=10)$, six patients developed severe acute pancreatitis (SAP) (three in group $\mathrm{A}$ and three in group B), and four patients developed mild acute pancreatitis (MAP), one in group $\mathrm{A}$ and three in group B with diclofenac use.

The average PEP hospitalization was $32.2 \pm 34.3$ days, with no statistically significant differences between groups $\mathrm{A}$ and $\mathrm{B}(\mathrm{P}=0.881)$. Four patients required a $\mathrm{CPU}$ bed; two in group $\mathrm{A}$ and two in group $\mathrm{B}(\mathrm{P}=0.548)$.

The average APACHE II in the PEP group was $8 \pm 3$ and $9 \pm 3$, in groups $A$ and $B$ respectively $(P=0.709)$. The average PCR was $23.7 \pm 26.2$ and $190.2 \pm 158.5$ in groups $A$ and $B$ respectively $(\mathrm{P}=0.125)$ (Table 3).

No patients died and there were no adverse reactions to the drug.

\section{Discussion}

PEP is one of the most frequent ERC complications and its prevention is a crucial topic to reduce the morbimortality in this patient group.

A meta-analysis in 2008 already showed the effectiveness of rectal NSAIDs in the PEP prevention (11).

Although the etiopathogenic mechanism is not absolutely clear, the prevention mechanism suggests that diclofenac acts at the inflammatory reaction level produced by the irritation of the pancreatic duct, because NSAIDs have a powerful inhibitory effect on phospholipase A2, a crucial element in the inflammatory cascade that produces acute pancreatitis.

Several agents have been studied with promising results; however, they include drugs not available anywhere in the world (gabexate and somatostatin) (12). By contrast, in addition to its clinical benefit, diclofenac is a low-cost drug, widely available, easy to administer and with a favorable side-effect profile, making it an attractive option.

The aim of the study was to verify if this simple PEP prevention measure could be replicated in a public hospital in southern Chile.

The PEP rate was higher in this report $(8.6 \%)$ than in a previous report provided by our group $(0.5 \%)$ (9). This is probably related to the greater complexity of the cases.

Our study showed that a $100 \mathrm{mg}$ dose of rectal diclofenac administration at the beginning of the procedure does not significantly reduce the PEP incidence. We had no adverse reactions to diclofenac nor mortality in our study.

Among the technical variables, a factor we consider important is that ERC is performed in the presence of two liver and pancreas surgeons (JSA and HLM) in most cases. This allows for team decision-making in difficult cases and to protocolize certain technical aspects like papillotomy size, use of precuts or use of balloon sphincteroplasty.

Although there is evidence showing that the use of rectal diclofenac reduces PEP rate, recent reports question its use in all patients undergoing an ERC.

A recent study with a sample of 1,000 patients with use of diclofenac compared to 1,000 historical controls without the use of diclofenac showed a PEP rate of $2.8 \%$ with no significant differences between the groups (13). 
Among the possible explanations for the lack of reduction in the PEP rate with rectal diclofenac is the reduced effect in the obese patients group, a very frequent reality in our hospital and unfortunately this variable was not recorded in the present study (14).

The stratification of the PEP risk and the use of diclofenac only in the high-risk group are controversial and evidence shows contradictory results $(7,13)$.

The combination of rectal diclofenac and other therapies that have shown effectiveness in reducing PEP rate seems attractive. One of the most economical therapies is crystalloid infusion in the peri-ERC period. Some works show that this association could have an effect on reducing PEP rate (15).

Our group will initiate a randomized clinical trial to assess whether the association of the crystalloid infusion in the peri-ERC period and rectal diclofenac reduces PEP rate.

There are some other tools that can be used to prevent PEP, such as the use of pancreatic prostheses in patients with repeated cannulations or opacification of the Wirsung duct (16-19). In the patients who present abdominal pain in the post-ERC period, the rescue ERC being performed by installing a Wirsung prosthesis could reduce the severity of PEP (20-22). We do not use these tools routinely, but we are starting a protocol to evaluate their effectiveness in our center.

\section{Conclusions}

The pancreatitis rate post-ERC was $8.6 \% \%(10 / 116)$ is similar to what has been described in the literature.

Rectally administered prophylactic diclofenac at the beginning of the ERC does not reduce the rate of PEP compared with the patients on whom the prophylaxis was not used.

\section{Acknowledgments}

Funding: Financed by DIUFRO Project No. 17-0062, Universidad de la Frontera, Chile.

\section{Footnote}

Data Sharing Statement: Available at http://dx.doi. org/10.21037/apm-19-395

Conflicts of Interest: All authors have completed the ICMJE uniform disclosure form (available at http://dx.doi. org/10.21037/apm-19-395). The authors have no conflicts of interest to declare.

Ethical Statement: The authors are accountable for all aspects of the work in ensuring that questions related to the accuracy or integrity of any part of the work are appropriately investigated and resolved. The study protocol was approved by the scientific ethics committee of the Araucanía South Health Service (Chile) and by the research group of the Department of Surgery Traumatology and Anesthesiology at the Universidad de la Frontera. All persons gave their informed consent prior to their inclusion in the study (ID: 004). The study was conducted in accordance with the Declaration of Helsinki (as revised in 2013).

Open Access Statement: This is an Open Access article distributed in accordance with the Creative Commons Attribution-NonCommercial-NoDerivs 4.0 International License (CC BY-NC-ND 4.0), which permits the noncommercial replication and distribution of the article with the strict proviso that no changes or edits are made and the original work is properly cited (including links to both the formal publication through the relevant DOI and the license). See: https://creativecommons.org/licenses/by-nc-nd/4.0/.

\section{References}

1. Sotoudehmanesh R, Khatibian M, Kolahdoozan S, et al. Indomethacin may reduce the incidence and severity of acute pancreatitis after ERCP. Am J Gastroenterol 2007;102:978-83.

2. Kylänpää L, Rakonczay Z, O'Reilly DA. The clinical course of acute pancreatitis and the inflammatory mediators that drive it. Int J Inflam 2012;2012:360685.

3. Murray B, Carter R, Imrie C, et al. Diclofenac reduces the incidence of acute pancreatitis after endoscopic retrograde cholangiopancreatography. Gastroenterology 2003;124:1786-91.

4. Mine T. Is post-endoscopic retrograde cholangiopancreatography pancreatitis the same as acute clinical pancreatitis? J Gastroenterol 2007;42:265-6.

5. Sheikh I, Fontenot E, Waghray N, et al. The role of nonsteroidal anti-inflammatory drugs in the prevention of post endoscopic retrograde cholangiopancreatography pancreatitis. JOP 2014;15:219-24.

6. Habtezion A. Inflammation in acute and chronic 
pancreatitis. Curr Opin Gastroenterol 2015;31:395-9.

7. Patil S, Pandey V, Pandav N, et al. Role of rectal diclofenac suppository for prevention and its impact on severity of post-endoscopic retrograde cholangiopancreatography pancreatitis in high-risk patients. Gastroenterology Res 2016;9:47-52.

8. Otsuka T, Kawazoe S, Nakashita S, et al. Low-dose rectal diclofenac for prevention of post-endoscopic retrograde cholangiopancreatography pancreatitis: a randomized controlled trial. J Gastroenterol 2012;47:912-7.

9. Losada H, Silva J, Burgos L. Experiencia en Colangiografía endoscópica retrógrada en Hospital Regional de Temuco: Serie de casos con seguimiento. Rev Chil Cir 2008;60:5-9.

10. Khoshbaten M, Khorram H, Madad L, et al. Role of diclofenac in reducing postendoscopic retrograde cholangiopancreatography pancreatitis. J Gastroenterol Hepatol 2008;23:e11-6.

11. Elmunzer BJ, Waljee AK, Elta GH, et al. A meta-analysis of rectal NSAIDs in the prevention of post-ERCP pancreatitis. Gut 2008;57:1262-7.

12. Andriulli A, Clemente R, Solmi L, et al. Gabexate or somatostatin administration before ERCP in patients at high risk for post-ERCP pancreatitis: a multicenter, placebo-controlled, randomized clinical trial. Gastrointest Endosc 2002;56:488-95.

13. Rainio M, Lindström O, Udd M, et al. Diclofenac does not reduce the risk of post-endoscopic retrograde cholangiopancreatography pancreatitis in low-risk units. J Gastrointest Surg 2017;21:1270-7.

14. Leerhøy B, Nordholm-Carstensen A, Novovic S, et al. Effect of body weight on fixed dose of diclofenac for the prevention of post-endoscopic retrograde cholangiopancreatography pancreatitis. Scand J

Cite this article as: Losada HF, San Martin PI, Troncoso AI, Silva JA. Rectal diclofenac for prevention of post-endoscopic retrograde cholangiography pancreatitis. Ann Palliat Med 2021;10(2):1336-1341. doi: 10.21037/apm-19-395
Gastroenterol 2016;51:1007-12.

15. Mok SRS, Ho HC, Shah P, et al. Lactated Ringer's solution in combination with rectal indomethacin for prevention of post-ERCP pancreatitis and readmission: a prospective randomized, oublé-blinded, placebocontrolled trial. Gastrointest Endosc 2017;85:1005-13.

16. Fazel A, Quadri A, Catalano MF, et al. Does a pancreatic duct stent prevent post-ERCP pancreatitis? A prospective randomized study. Gastrointest Endosc 2003;57:291-4.

17. Singh $P$, Das A, Isenberg $G$, et al. Does prophylactic pancreatic stent placement reduce the risk of post-ERCP acute pancreatitis? A meta-analysis of controlled trials. Gastrointest Endosc 2004;60:544-50.

18. Mazaki T, Masuda H, Takayama T. Prophylactic pancreatic stent placement and post-ERCP pancreatitis: a systematic review and meta-analysis. Endoscopy 2010;42:842-53.

19. Choudhary A, Bechtold ML, Arif M, et al. Pancreatic stents for prophylaxis against post-ERCP pancreatitis: a meta-analysis and systematic review. Gastrointest Endosc 2011;73:275-82.

20. Madácsy L, Kurucsai G, Joó I, et al. Rescue ERCP and insertion of a small-caliber pancreatic stent to prevent the evolution of severe post-ERCP pancreatitis: a casecontrolled series. Surg Endosc 2009;23:1887-93.

21. Fejes R, Kurucsai G, Székely A, et al. Feasibility and safety of emergency ERCP and small-caliber pancreatic stenting as a bridging procedure in patients with acute biliary pancreatitis but difficult sphincterotomy. Surg Endosc 2010;24:1878-85.

22. Ding G, Qin M, Cai W, et al. The safety and utility of pancreatic duct stents in the emergency ERCP of acute biliary pancreatitis but difficult sphincterotomy. Hepatogastroenterology 2012;59:2374-6. 